\title{
ethic@

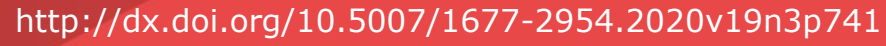 \\ MICHEL FOUCAULT E GIORGIO AGAMBEN: CONVERGÊNCIAS E DIVERGÊNCIAS TEÓRICAS SOBRE PODERES E POTÊNCIAS
}

\author{
MICHEL FOUCAULT AND GIORGIO AGAMBEN: THEORETICAL \\ CONVERGENCES AND DIVERGENCES ABOUT POWERS AND \\ POTENCIES
}

\author{
CARLOS HENRIQUE AGUIAR SERRA ${ }^{1}$ \\ (UFF/BRASIL)
}
LUÍS ANTÔNIO FRANCISCO DE SOUZA²
(UNESP/BRASIL)

RAPHAEL GUAZZELI VALERIO ${ }^{3}$

(UFPE/BRASIL)

\begin{abstract}
RESUMO
O presente artigo teórico identifica as convergências e divergências entre as obras de Giorgio Agamben e de Michel Foucault. Pretende-se discutir o pensamento político de Giorgio Agamben no que concerne às suas formulações sobre estado de exceção em contraste com as formulações de Michel Foucault sobre biopolítica. Uma convergência visível é a importância da noção de dispositivo e de biopolítica na obra dos dois autores. Em Foucault o acento se dá nas práticas cotidianas, por assim dizer, do exercício de poder, tendo foco o conceito de genealogia. Agamben procura dar mais ênfase, sem dúvida, ao estado de exceção e à vida nua. No que diz respeito à postura dos dois autores em relação à resistência aos poderes, o artigo aponta, em Foucault, todo seu exercício voltado ao tema do cuidado de si e da vontade de verdade e, em Agamben, numa evidente inspiração messiânica ao gênero de Walter Benjamin, como é possível pensar na comunidade que vem, que tem a potência de superar o paradigma da vida nua e seu correlato imediato, a soberania.
\end{abstract}

Palavras-chave: Michel Foucault; Giorgio Agamben; Estado de Exceção; Dispositivo; Paradigma; Biopolítica; Potência.

\footnotetext{
ABSTRACT

This paper identifies the convergences and divergences between the works of Giorgio Agamben and Michel Foucault. It aims to discuss the political thought of Giorgio Agamben regarding his formulations about the state of exception against Michel Foucault's wordings about biopolitics. A visible convergence is the importance of the notion of apparatus and biopolitics in the work of both authors. In Foucault, the accent is on everyday practices, so to speak, of the exercise of power, focusing on the concept of genealogy. Agamben undoubtedly seeks to
} 
emphasizes the state of exception and bare life. With regard to the position of the two authors in relation to resistance to powers, the article points out, in Foucault, all of his exercise focused on the theme of self-care and the will to truth and, in Agamben, in an evident messianic inspiration to the genre of Walter Benjamin, how it's possible to think about the coming community, which has the power to overcome the paradigm of bare life and its immediate correlate, sovereignty.

Keywords: Michel Foucault; Giorgio Agamben; State of Exception; Apparatus; Paradigm; Biopolitics; Potency.

\section{Introdução}

O propósito do presente artigo é buscar as convergências e divergências entre as obras de Giorgio Agamben e de Michel Foucault. Interessa aqui refletir a respeito do pensamento político de Giorgio Agamben no que concerne mais especificamente às suas formulações teóricas sobre a noção de estado de exceção, em sua conexão com as formulações de Foucault sobre biopolítica. Com este debate, pretende-se realizar uma genealogia da política contemporânea. Uma aproximação mais visível entre Agamben e Foucault reside na importância dada pelos autores à noção de biopolítica, muito embora seus olhares sejam distintos.

Giorgio Agamben, nascido em 1942, comenta aspectos da obra de Michel Foucault quando publica Homo Sacer em 1995. Uma primeira distinção significativa existente entre Agamben e Foucault diz respeito aos procedimentos metodológicos: em Foucault, observa-se sua opção por uma genealogia do poder que é um procedimento de uma história do presente. Giorgio Agamben procede a uma hermenêutica política dos conceitos. Sua proposta consiste numa explicitação da relação entre a potência do vivente e os dispositivos políticos. ${ }^{4} \mathrm{O}$ que chamamos de sujeito é o resultado de uma tensão entre poder e potência, entre controles e vida política.

A genealogia de Foucault possui como referência fundamental a perspectiva teórico-metodológica de Nietzsche na medida em que se "opõe à pesquisa de origem" (FOUCAULT, 1984, p. 12). Em meados dos anos 1970, Foucault produziu uma ruptura epistemológica em relação à tradição dos estudos sobre poder, na medida em que desvinculou o poder da análise específica do Estado. Assim, o poder passou a ser tomado como estratégia de dominação, como forma de produção de verdade e como constituição de sujeitos. Interessou a ele estudar a mecânica do poder. A biopolítica, em Foucault, corresponde à modalidade de poder que incide sobre coletividades vivas, dentro do princípio do poder que faz viver e deixa morrer. Em Agamben, a política aparece com sendo sempre biopolítica, pois ela é constituída pelo procedimento do estado de exceção, em que a vida nua é 
tematizada pelo político (LEMKE, 2003; AGAMBEN, 2004; FOUCAULT, 1999).

Ao final, pretendemos tematizar como estas divergências e convergências também se constroem no campo da resistência. Em Foucault o acento se dá nas práticas cotidianas, por assim dizer, do exercício de poder. A genealogia é uma arma crítica, a um só tempo, contra os discursos e as práticas. Agamben explora as possibilidades de resistência num campo meta-teórico. Numa clara inspiração messiânica ao gênero de Walter Benjamin, se propõe a pensar uma comunidade que vem contra o biopoder. Esta comunidade deve superar o paradigma da vida nua e seu correlato imediato, a soberania.

\section{Dispositivo ou paradigma?}

Um dos eixos da comparação metodológica entre os dois autores é o uso do conceito de dispositivo. Foucault concebe o dispositivo como um conjunto de discursos, instituições, arquiteturas, leis e regulamentos. O dispositivo estabelece uma rede entre esses elementos heterogêneos. 0 dispositivo tem uma função estratégica e sua configuração histórica muda. Em outros termos, dispositivo articula estratégias de poder, discursos de verdade, processos de subjetivação. Esse tripé hermenêutico proposto por Foucault está presente em suas análises, mutatis mutandis, desde a História da Loucura até a História da Sexualidade. Neste sentido, pode-se falar em dispositivo da sexualidade, dispositivo disciplinar e dispositivo biopolítico, considerando o caráter ao mesmo tempo analítico e histórico dos dispositivos. O dispositivo, portanto, abrange processos abstratos e estratégias concretas (REVEL, 2011).

Para Agamben, dispositivo é tudo o que tenha "capacidade de capturar, orientar, determinar, interceptar, modelar, controlar e assegurar os gestos, as condutas, as opiniões, os discursos dos seres viventes" (AGAMBEN, 2009, pg. 40). O dispositivo não se refere apenas às prisões e seus discursos, às fábricas e suas técnicas, às disciplinas e ao direito, mas também os objetos, por mais simples que possam ser, como a caneta, o cigarro, os computadores etc. A linguagem, neste sentido, é um dos mais antigos dispositivos (AGAMBEN, 2009, pp. 40-41). Sendo assim, Agamben amplia o conceito de Foucault na medida em que dispositivo compreende os aparatos criados pelo homem em razão de sua funcionalidade (VALERIO, 2019 , p. 36). Mas é preciso reforçar a ideia segundo a qual o dispositivo é um conceito aglutinador a partir do qual o que se pretende frisar são as diferentes formas de captura de corpos e ações humanas. Sendo assim, o estado de exceção não é uma limitação do domínio jurídico-político, mas, 
sim, articula as estratégias concretas dentro/fora da lei. A articulação entre estado de exceção e biopolítica torna-se necessária, na forma de um paradigma.

Assim, diferente de Foucault, Agamben propôs um novo sentido para o conceito de paradigma. Os problemas teóricos, políticos, filosóficos, jurídicos não são apenas fenômenos históricos; são, na verdade, paradigmas que expressam a relação fundamental entre vida e poder. Ou seja, são exemplos, singularidades ou modelos que permitem tornar inteligíveis os processos. As regras científicas gerais são substituídas pelo paradigma assim como a lógica universal da lei é tomada como exemplo ou como um caso singular (AGAMBEN, 2009, pp. 13-16). Exemplificando: a lei pressupõe o não jurídico assim como o direito pressupõe a exceção; a política pressupõe o campo de concentração etc. Há uma relação potencial entre o geral e o particular, entre normal e patológico, entre norma e exceção. "A linguagem é o soberano que, em permanente estado de exceção, declara que não existe um fora da língua, que ela está sempre além de si mesma" (AGAMBEN, 2004, p. 29).

Portanto, o conceito de paradigma ou de exemplo permite evitar os pares antinômicos. O termo grego para-deígma refere-se àquilo que se coloca ao lado. Sendo assim, para o autor, paradigma significa: 1) todos os casos do mesmo gênero e está, ao mesmo tempo, incluído entre esses casos; 2) é uma singularidade entre outras e, ao mesmo tempo, vale por todas elas; 3 ) é um caso particular real e, ao mesmo tempo, como exemplo, não pode valer como particularidade. "Nem particular nem universal, o exemplo é um objeto singular que, digamos assim, se dá a ver como tal, mostra a sua singularidade" (AGAMBEN, 1993, p. 16; VALERIO, 2019, p. 61). Ou seja, no conceito de paradigma, a exceção se torna permanente e, portanto, ocupa o lugar da regra, do direito. O poder soberano e o direito dependem da exceção (a zoé ocupa o lugar da bíos e constitui uma vida nua como paradigma da política na modernidade), se confundem com a exceção, que é seu exemplo mais paradigmático.

Sendo assim, "paradigma é uma forma de conhecimento (...) analógica", no singular; ele neutraliza a oposição entre o geral e o particular; o paradigma é exemplar e singular ao mesmo tempo; o paradigma tem uma história, mas não é da ordem da arché. A historicidade do paradigma "não está nem na diacronia nem na sincronia, mas no entrecruzamento delas" (AGAMBEN, 2009, pp. 156-157). Portanto, a partir destas considerações da proximidade metodológica entre os autores, podemos analisar o estado de exceção como paradigma da modernidade.

\section{Estado de exceção e vida nua}


Giorgio Agamben realiza um diálogo com Walter Benjamin e Carl Schmitt sobre a noção de estado de exceção ${ }^{5}$. Mas em Homo Sacer, Agamben reconhece a importância da discussão de Michel Foucault sobre biopolítica. Agamben ao mesmo tempo em que reconhece, faz reparos e se apropria das formulações de autores anteriores. Ele afirma que talvez Foucault "jamais tenha deslocado a sua investigação para as áreas por excelência da biopolítica moderna: o campo de concentração e a estrutura dos grandes estados totalitários dos Novecentos", afinal, "o ingresso da zoée na esfera da polis, a politização da vida nua como tal constitui o evento decisivo modernidade, que assinala uma transformação radical das categorias político-filosóficas do pensamento clássico" (AGAMBEN, 2002, p. 12).

Para Agamben, o diálogo mais profícuo deveria ter sido entre Foucault e Arendt, já que as "duas análises não podem ser separadas e que a implicação da vida nua na esfera política constitui o núcleo originário - ainda que encoberto - do poder soberano". Nestes termos, a biopolítica é uma invenção antiga, já que ao colocar "a vida biológica no centro de seus cálculos, o Estado moderno não faz mais, portanto, do que reconduzir à luz o vínculo secreto que une o poder à vida nua" (AGAMBEN, 2002, p. 14).

Agamben ainda é mais contundente no postulado de que a "dupla categorial fundamental da política ocidental não é aquela amigo-inimigo, mas vida nua- existência política, zoé-bíos, exclusão-inclusão" (AGAMBEN, 2002, p.16). Desta forma, segundo o autor, a política existe porque o "homem é o vivente que, na linguagem, separa e opõe a si a própria vida nua e, ao mesmo tempo, se mantém em relação com ela numa exclusão inclusiva" (AGAMBEN, 2002, p. 16). A divergência de Agamben em relação a Foucault fica assim evidenciada no paradoxo de uma "vida matável e insacrificável do homo sacer". Sendo assim,

Lado a lado com o processo pelo qual a exceção se torna em todos os lugares a regra, o espaço da vida nua, situado originariamente à margem do ordenamento, vem progressivamente a coincidir com o espaço político, e exclusão e inclusão, externo e interno, bíos e zoé, direito e fato entram em uma zona de irredutível indistinção (AGAMBEN, 2002, p.16).

Então, há uma imbricação necessária, no âmbito do Estado contemporâneo, entre a biopolítica, poder soberano e estado de exceção. Para Agamben, o "estado de exceção apresenta-se como forma legal daquilo que não pode ter forma legal" e mais, apresenta-se como um 
"patamar de indeterminação entre democracia e absolutismo" (AGAMBEN, 2004, p. 12). "[E]star-fora e, ao mesmo tempo, pertencer: tal é a estrutura topológica do estado de exceção, e apenas porque o soberano que decide sobre a exceção é, na realidade, logicamente definido por ela em seu ser, é que ele pode também ser definido pelo oxímoro êxtase-pertencimento" (AGAMBEN, 2004, p. 57). Há uma imbricação de inúmeros elementos e é possível refletir a respeito da possibilidade interpretativa de conexões entre o estado de exceção, Estado absoluto e o Estado de direito; lógica do inimigo e cultura punitiva. Um aspecto muito relevante na definição do estado de exceção é que ele é um vazio de Direito, um "espaço anômico onde o que está em jogo é uma força-de-lei sem lei" (AGAMBEN, 2004, p. 61).

Sendo assim, as incongruências aparentes do Estado de Direito no Brasil - consagração de direitos civis e políticos e militarização crescente ficam esclarecidas.

O espaço político da soberania ter-se-ia constituído, portanto, através de uma dupla exceção, como uma excrescência do profano e no religioso e do religioso no profano, que configura uma zona de indiferença entre sacrifício e homicídio. Soberana é a esfera na qual se pode matar sem cometer homicídio e sem celebrar um sacrifício, e sacra, isto é, matável e insacrificável, é a vida que foi capturada nesta esfera. (AGAMBEN, 2002. p. 91).

O conceito de estado de exceção pode aparecer sob três aspectos: a) como uma categoria analítica para caracterizar uma situação singular de indeterminação; b) como exceção permanente; c) a supressão da política (SANTOS, 2007). Trata-se então de uma exceção permanente, mesmo sem a supressão das leis. Isto porque a lei, para ser aplicada, é, ao mesmo tempo, desaplicada; o estado de exceção, assim, ativa e desativa o dispositivo guerreiro (AGAMBEN, 2004, p. 27-28).

O poder político se funda no isolamento e na separação do simples fato de viver, a vida nua, de suas formas qualificadas de viver. O nexo entre política e vida nua já está presente na clássica definição aristotélica do homem como animal que possui linguagem (zoon logon ekhon). Segundo Aristóteles, a política se funda a partir da linguagem e não da voz. A voz, comum a todos os animais, é capaz de exprimir o prazer e o desprazer; a linguagem, por seu turno, atributo humano, expressa o justo e o injusto e, por isso, pode fundar a comunidade. Observe-se, então, que é a relação vida e política que está em jogo na passagem da voz (phoné) à linguagem (lógos) (VALERIO, 2019, p. 42-44). Decisivo é que, conjuntamente ao 
processo moderno pelo qual a exceção torna-se regra, o espaço da vida nua, originalmente à margem do ordenamento jurídico, coincida com o espaço político. De modo que zoé e bíos, direito e fato, inclusão e exclusão, entrem em uma zona de indistinção e possam ser tomados um pelo outro (VALERIO, 2019, p. 45) ${ }^{6}$.

\section{Biopolítica e tanatospolítica}

Michel Foucault é um dos principais teóricos contemporâneos a respeito das instituições disciplinares existentes no capitalismo. De sua obra, interessa recuperar especificamente as formulações desenvolvidas a respeito do conceito de biopolítica e sobre os mecanismos da punição disciplinar. A hipótese central que Foucault elabora é que, para além da dominação repressiva sobre uma classe trabalhadora, é necessário compreender o como do poder em termos de seu exercício e de seus efeitos de disciplinamento geral da sociedade (FOUCAULT, 1979).

A disciplina implica uma nova estratégia para o exercício do poder de punir cujo objetivo era punir com eficiência e com minimização da dor física, reduzindo a possibilidade de resistência. Assim, o poder não é visto em seu aspecto jurídico, segundo o modelo da soberania, mas em seu efeito estratégico, segundo o modelo da guerra (FOUCAULT, 1984). Assim, Foucault pensa a disciplina enquanto forma de constituição de sujeitos mais do que uma forma de dominação política. O momento histórico das disciplinas é aquele em que nasce uma arte que incide sobre o corpo humano, para produzir corpos viáveis para a nascente sociedade disciplinar (FOUCAULT, 1984). A arte de punir é uma estratégia política que aumenta a submissão e diminui a revolta. Mais do que isto, a punição é para além de uma inflição de dor sem sentido, pois o que se almeja é um excesso punitivo, de forma sacralizada, infame e racional (ZAFFARONI, 1991). A disciplina tem um papel político na medida em que a pena de prisão corresponde à privação de liberdade e sua expressão máxima encontra-se no panóptico.

A biopolítica configura-se numa forma de poder que diferentemente da disciplina passa a se exercer sobre coletividades, sobre multiplicidades. Michel Foucault (1985), no capítulo, "Direito de morte e poder sobre a vida", aponta para o papel da biopolítica como mecanismo de gestão da vida, tratando-se de um poder que investe sobre o ser humano como ser vivo, como população, de onde se pode extrair um determinado quantum de ação ótima, tendendo para uma normalização do corpo social.

Ora, agora que o poder é cada vez menos o direito de fazer morrer e cada vez mais o direito de intervir para fazer viver, 
e na maneira de viver, e no 'como' da vida, a partir do momento em que, portanto, o poder intervém sobretudo nesse nível para aumentar a vida, para controlar seus acidentes, suas eventualidades, suas deficiências, daí por diante a morte, como termo da vida, é evidentemente o termo, o limite, a extremidade do poder. Ela está de do lado de fora, em relação ao poder: é o que cai fora de seu domínio, e sobre o que o poder só terá domínio de modo geral, global, estatístico. Isso sobre o que o poder tem domínio não é a morte, é a mortalidade. $\mathrm{E}$, nessa medida, é normal que a morte, agora, passe para o âmbito privado e do que já de mais privado. Enquanto, no direito de soberania, a morte era o ponto em que mais brilhava, da forma mais manifesta, o absoluto do poder do soberano, agora a morte vai ser, ao contrário, o momento em que o indivíduo escapa a qualquer poder, volta a si mesmo e ensimesma, de certo modo, em sua parte mais privada. O poder não conhece a morte. No sentido estrito, o poder deixa a morte de lado (FOUCAULT, 1999, p. 295-296).

A partir da segunda metade do século XVIII, política médica, higiene pública e medicina social já podiam ser inscritas nos quadros de uma biopolítica. O que caracteriza este poder geral é a população como um conjunto de seres vivos, com especificidades geográficas, históricas e políticas. A população demanda técnicas e saberes diversos do poder disciplinar. No século XVIII, novos problemas, novas técnicas e novos objetos políticos e econômicos demandam um conjunto novo de dispositivos que tentam controlar as vidas humanas.

Giorgio Agamben (2002) retoma a hipótese biopolítica de Foucault. A principal diz respeito à temporalidade do biopoder. Para Foucault a política se transmuta em biopolítica a partir do século XVIII, para Agamben a política nasce como biopolítica. Para Foucault, trata-se de analisar os dispositivos concretos por meio dos quais o poder se relaciona com a vida e com os corpos. Agamben analisa o discurso jurídico-político das teorias clássicas do poder, em especial a soberania, supostamente deixadas de lado por Foucault. Mas as principais mudanças na noção de biopolítica em Agamben dizem respeito ao sentido da vida, ou melhor, ao processo de submissão da vida nua ao quadro mais amplo dos dispositivos do poder soberano, por meio do paradigma do campo de concentração. Trata-se, portanto, de uma expansão da biopolítica para as estratégias de matabilidade das vidas que não merecem ser vividas e da disponibilidade dos corpos aos ensaios do poder, quer pela psiquiatria, medicina ou economia. O que está em jogo, portanto, é o valor próprio da vida e as 
qualidades específicas atribuídas ao ser humano, incluindo a definição mesma do humano na modernidade, de seu caráter sagrado, mas insacrificável.

O sentido do sagrado deve ser esclarecido e questionado, segundo a metodologia da superação das aporias proposta por Agamben. Sacer é uma palavra ambígua. Significa ao mesmo tempo abjeto, ignominioso e augusto, reservado aos deuses. E sacros são a tanto a lei como aquele que a protege e a viola. "Aquele que violou a lei, em particular o homicida, é excluído da comunidade, é, pois, repelido, abandonado a si mesmo e, como tal, pode ser morto sem delito" (AGAMBEN, 2006, p. 142). No direito romano antigo, aparece esta ambigüidade na forma da sacratio que decreta a impunidade da morte e a exclusão do sacrifício; a consagração que faz a vítima do ato sacrifical passar do direito humano ao divino, do profano ao sacro. No caráter indiscernível do sagrado é que reside a peculiaridade do homo sacer, pois ele é colocado fora do direito humano, sua morte não é punível, e, ao mesmo tempo não pode ser consagrado. Sagrado e matável, esta é a aporia. No estado de exceção, a vida protegida pelos estatutos jurídicos democráticos, portanto, considerada sagrada, representa também esta duplicidade, pois é ao mesmo tempo divina, portanto, insacrificável, e humana, portanto, matável. "A vida insacrificável e, todavia, matável, é a vida sacra" (AGAMBEN, 2006, p. 90).

A vida capturada pelo de fora da soberania, o bando soberano, não tem substrato nem essência, é uma pura relação de duplo vínculo: exclusão inclusiva ou inclusão exclusiva. "Soberana é a esfera na qual se pode matar sem cometer homicídio e sem celebrar um sacrifício, e sacra, isto é, matável e insacrificável, é a vida que foi capturada nesta esfera" (AGAMBEN, 2006, p. 91). A reivindicação do caráter sagrado da vida é sua exposição a um poder de morte (VALERIO, 2018, p. 78-79). Portanto, "Nem bíos político, nem zoé natural, a vida sacra é a zona de indistinção na qual implicandose e excluindo-se um ao outro, estes se constituem mutuamente" (Agamben, 2006, p. 98). No mundo contemporâneo, a politização da vida, sua captura tanto pelo dispositivo biopolítico como pela disciplina produz esta cesura entre a vida e a vida nua, que é indigna de ser vivida, sendo que esta última penetra profundamente nas vidas de todos os seres humanos que, agora, são definidos pelo seu grau de descartabilidade. A implicação da vida nua na vida política torna todos os seres humanos potencialmente excedentes. Ou seja, neste momento, o estado de exceção produz não mais o bíos, mas o tanatos, assim, a biopolítica converte-se em tanatospolítica.

$\mathrm{Na}$ reflexão de Agamben, a concepção de espécie humana como partícipe de corpo político não impede a ativação da zoé no cerne da bíos. 
"Ou seja, o povo já traz sempre em si a fratura biopolítica fundamental. Ele é aquilo que não pode ser incluído no todo do qual faz parte e não pode pertencer ao conjunto no qual já está desde sempre incluído". (AGAMBEN, 2015, p. 37. Grifos no original).

\section{Michel Foucault: ética e política na luta contra toda forma de poder.}

Parafraseando Bertold Brecht, numa época em que as forças do bem parecem estar mais fracas é que precisamos demonstrar mais vitalidade e entusiasmo na luta política. Michel Foucault, ao longo da sua vasta obra, deixou abertas várias pistas para uma reflexão sobre resistência ao poder e aos efeitos de verdade dos discursos. Ao lado de um vigoroso percurso filosófico, Foucault desenvolveu uma trajetória consistente e intensa de confrontações e lutas políticas (DREYFUS \& RABINOW, 2010; ERIBON, 1989). As abordagens variam de acordo com seus posicionamentos estratégicos, sendo que a análise mais intensa sobre resistência se encontra nos debates em torno de Vigiar e Punir e de sua ação no Grupo de Informações sobre Prisões (GIP) (ALVAREZ, 2006). Na conversa com Gilles Deleuze (FOUCAULT, 1989), estas questões ficam esclarecidas: na luta política, o intelectual tem uma posição estratégica na medida em que não mais representa a consciência social totalizante. Ele passa a lutar ao lado dos grupos e movimentos sociais já que a relação entre teoria e prática se alterou e o intelectual não pode mais se colocar fora da ideologia contra a qual pretende desferir sua crítica.

Neste sentido, a prática política é, ao mesmo tempo, crítica teórica, estratégia local de luta e coragem de enfrentar uma luta cujas vitórias podem ser parciais. Esta situação de um poder que se exerce em todas as dimensões da vida social requer um intelectual específico, local e regional, que, ao lado dos movimentos, busque fazer a crítica teórica e política e não se contente em ser representante de uma classe ou de um grupo, mas que se coloque no mesmo nível de quem luta. Este, aliás, é o papel da genealogia do poder, pois não se trata apenas de uma forma de conhecimento, mas é também um estratégia contra-política: "A genealogia é uma arma contra o poder, contra todos os poderes" (EWALD, 1993, p. 27). E esta arma é mais urgente diante da ameaça provocada pelos avanços da governamentalidade digital em escala global, que começa a tomar conta de todos os aspectos de nossas vidas, públicas, privadas e íntimas (DELEUZE, 1999; SOUZA, 2006). Ameaça com várias facetas: de um poder que passa a ser exercido como biopoder, numa engrenagem tecnológica panóptica ampliada pelas tecnologias digitais; do pastorado neofascista fundamentalista com suas mais detidas estratégias de confissão, exame e 
ódio. As análises da História da Sexualidade I, a vontade de saber, delinearam todos os efeitos da inscrição deste poder ao mesmo tempo múltiplo e diverso, coletivo e individual, em que se articulam a anátomopolítica do corpo individual e a biopolítica da população: "o poder ganha impulso pelo seu próprio exercício; o controle vigilante é recompensado por uma emoção que o reforça; a intensidade da confissão relança a curiosidade do questionário; o prazer descoberto reflui em direção ao poder que o cerca" (FOUCAULT, 1985, p. 44-45). São estas técnicas ao mesmo tempo incitadoras do discurso sobre o sujeito e excitadora da esfera íntima desvelada e devassada pelos poderes. Somos constituídos por um poder meticuloso e examinados por um saber curioso: "O homem, no Ocidente, tornou-se um animal confidente" (FOUCAULT, 1985, p. 59):

Ora, a confissão é um ritual de discurso onde o sujeito que fala coincide com o sujeito do enunciado; é, também, um ritual que se desenrola numa relação de poder, pois não se confessa sem a presença ao menos virtual de um parceiro, que não é simplesmente o interlocutor, mas a instância que requer a confissão, impõe-na, avalia-a e intervém para julgar, punir, perdoar, consolar, reconciliar; um ritual onde a verdade é autenticada pelos obstáculos e as resistências que teve de suprimir para poder manifestar-se; enfim, um ritual onde a enunciação em si, independentemente de suas consequências externas, produz em quem a articula modificações intrínsecas: inocenta-o, resgata-o, purifica-o, livra-o de suas faltas, libera-o, promete-lhe a salvação (FOUCAULT, 1985, p. 61).

Diante desta captura meticulosa, Michel Foucault não recua diante do olhar fixo da Górgona; ele demonstra que é possível desativar os poderes e os saberes, pensar diferente, agir de forma diversa, liberar a potência e a transgressão; não temos outra opção senão dizer sim à existência (RAGO, 2009).

No prefácio ao Anti-Édipo de Deleuze e Guatarri, de 1977, Foucault exerce este poder de síntese ao afirmar que o livro exorta a uma vida não fascista segundo a qual não devemos ter amor pelo poder, nem por soluções finalísticas, nem por promessas redentoras. A vida não fascista corresponde a uma atitude de destruição das verdades absolutas e dos poderes estabelecidos, e esta atitude requer coragem, fervor, arte e irreverência (FOUCAULT, 1977; RAGO \& VEIGA-NETO, 2009).

$\mathrm{Na}$ conferência proferida na Sociedade Francesa de Filosofia, em 1978, Foucault reflete sobre o papel da crítica, tendo como pano de fundo A discussão de Kant sobre o sentido da Aufklärung como "coragem de 
verdade". A crítica refere-se não ao caráter utilitário do conhecimento e mais ao seu uso público. O foco da crítica deve estar no "movimento pelo qual o sujeito se dá o direito de interrogar a verdade sobre seus efeitos de poder e o poder sobre seus discursos de verdade; pois bem, a crítica será a arte da inservidão voluntária, aquela da indocilidade refletida." Como é possível, no interior mesmo da estrutura do saber e do poder dominantes, produzir uma atitude ao mesmo tempo de confronto político e de verdade sobre si? A "coragem de verdade" é a resposta, retomada na forma do debate em torno da parresía (FOUCAULT, 2011), da palavra franca e todas as suas implicações éticas e políticas (MARTINS, 2009). Como é possível, portanto, fazer a crítica e que esta não esteja restrita à esfera do pensamento filosófico? Michel Foucault resume assim a questão:

Como a indissociabilidade do saber e do poder no jogo das interações e das estratégias múltiplas pode induzir ao mesmo tempo singularidades que se fixam a partir de suas condições de aceitabilidade e um campo de possíveis, de aberturas, de indecisões, de retornos e de deslocamentos eventuais que os tornam frágeis, que os tornam impermanentes, que fazem desses efeitos dos acontecimentos nada mais, nada menos que acontecimentos? De qual forma os efeitos de coerção próprios a essas positividades podem ser, não dissipados por um retorno ao destino legítimo do conhecimento e por uma reflexão sobre o transcendental ou o quase transcendental que o fixa, mas invertidos ou desfeitos no interior de um campo estratégico concreto que os induziu, e a partir da decisão precisamente de não ser governado? (FOUCAULT, 1990, p. 40).

Decisão soberana da liberdade individual como parresía cujo precedente teórico e prático é o cuidado de si (epimeleia heautou). Em 1984, Foucault anuncia, no volume II da História da Sexualidade (2007), a mudança do seu projeto de investigação de uma genealogia do poder sobre a sexualidade para uma "reflexão sobre a autoconstrução da liberdade", isto é, sobre o cuidado de si. A proposta é uma visada sobre o conteúdo ético das práticas sexuais dos gregos no que ele chamou de "artes da existência". Ou seja, "entender, com isso, práticas refletidas e voluntárias através das quais os homens não somente se fixam regras de conduta, como também procuram se transformar, modificar-se em seu ser e fazer de sua vida uma obra que seja portadora de certos valores estéticos e responda a certos critérios de estilo" (FOUCAULT, 2007, p. 14-15). Trata-se então de pensar as formas de construção do sujeito, como elaboração de trabalho ético e não como sujeição às regras e interdições de uma moral austera. A 
problematização ética da ação, assim, é caminho possível porque já percorrido na história do ocidente de construção de práticas de si. São várias práticas de si reveladas por Michel Foucault que apontam para a enkrateia (domínio de si) como exercício da liberdade, como ato de bravura e de coragem: "uma forma ativa de domínio de si que permite resistir ou lutar e garantir sua dominação no terreno dos desejos e dos prazeres" (FOUCAULT, 2007, p. 61). Desta forma, a liberdade entre os gregos "é entendida como autodomínio, como exercício de si para si e, portanto, como autogoverno" (FOUCAULT, 2007, p. 79). Então, o cuidado de si refere-se a um preceito, doutrina, prática individual e social, forma de vida que o sujeito adota como ocupação para consigo mesmo (FOUCAULT, 1985, p. 55). Trata-se de resgatar o sentido do princípio socrático que articula o domínio de si com uma postura filosófica segundo a qual uma vida não examinada não merece ser vivida.

Liberdade, então, não é uma ausência de ação; Foucault procurou construir uma via diversa da noção política da liberdade jurídica. Liberdade tem relação com o exercício do sujeito sobre si mesmo, como uma arte de viver; a askesis não pode ser adquirida sem "um treino de si por si mesmo". Lembra Foucault de Plutarco: "a escrita de si tem uma função ethopoiética: transforma a verdade em ethos" (FOUCAULT, 2004, p. 147). A luta política, a ação ética e a vontade de verdade são os componentes da resistência no mundo contemporâneo. As lições arqueológicas, genealógicas e éticas de Michel Foucault são um antídoto poderoso contra estes poderes que, cada vez mais, ameaçam a liberdade, a qualidade e sustentabilidade de nossa vida no presente.

\section{Giorgio Agamben: superar a vida nua é superar a soberania}

Se percorrermos toda obra de Giorgio Agamben veremos que a experiência ocidental da qualificação da vida humana enquanto vida política passa por uma inclusão exclusiva7. Explica-se. A vida em sua nudez enquanto suporte último dos gêneros de vida, isto é, enquanto vida política e autárquica, precisa ser separada e dividida e, ao mesmo tempo, necessita ser incluída como a negatividade da pólis. Em suma, a vida nua é incluída na comunidade política por meio de sua suspensão, sua exclusão.

A estrutura, ou melhor, a topologia da inclusão exclusiva da vida nua obedece aos mesmos procedimentos observados na constituição da soberania. Dizer que o soberano, no ato político originário, isto é, o da decisão, está ao mesmo tempo dentro e fora da lei, é dizer que a lei se aplica desaplicando-se da normalidade. O caso excepcional, a substância da 
decisão, é incluído na normalidade legal por meio de sua suspensão, quer dizer, exatamente como uma exceção.

Definamos a política como uma máquina ontológico-biopolítica (AGAMBEN, 2017, p. 229). A máquina politiza a vida, dá a ela um caráter político ao dividi-la, de um lado a vida nua, zoé, de outro a vida qualificada, bíos. Todavia, o centro desta máquina, onde tudo se passa, está vazio, ela não tem outro conteúdo que não a cesura, a separação em si mesma. A máquina se deixa ver somente porque já está construída a partir de separações. Biopolítica portanto, mas também ontológico-política, pois, do modo como as coisas se passam poderíamos dizer que, conforme Agamben, a política como obra do humano ${ }^{8}$ é uma práxis em que o lógos separa aquilo que é inseparável, quer dizer, a vida vegetativa da vida qualificada, o fato da vida da forma como levamos a vida.

Se recorrermos ao modelo da sacratio, o dispositivo teológico-político fundamental para a constituição do Estado e da soberania, podemos ver como a vida nua é um correlato imediato do homo sacer, quer dizer, um artifício. Não há, em verdade, um puro fato da vida, uma vida em sua nudez biológica, para destinar um homem a ser sacer é necessária uma decisão jurídica. O conteúdo próprio da sacralidade do condenado é carente de substância, é a passagem, o vazio da máquina.

Gostaríamos de defender, na esteira de Agamben, a ideia de que a possibilidade do Estado se dá justamente neste artifício de inclusão exclusiva. O Estado ocuparia este não-lugar da decisão soberana, onde somos suspensos e separados de nós mesmos; a vida, nossa vida passaria, pois, por estas cisões incessantes realizadas no interior da máquina biopolítica-estatal, onde a vida qualificada e desqualificada é produzida, lançando mão de um sem números de dispositivos que, ao final, são todos dispositivos políticos de formação humana. O Estado, insistimos, é o lócus da produção da vida politizada que assim o faz ao separar, metafisicamente vale dizer, o inseparável.

Sabemos que $O$ uso dos corpos (AGAMBEN, 2017) é o último trabalho da extensa pesquisa do filósofo italiano em torno da figura do homo sacer e suas consequências para o Ocidente. Próximo das últimas linhas desta obra Agamben repete uma passagem que já havia elaborado no início de seu projeto (AGAMBEN, 2015, p. 18). Nela há uma afirmação e uma pergunta ambas de caráter asseverativo ${ }^{9}$, messiânico diriam alguns; ei-la: Uma vida política, ou seja, orientada pela ideia de felicidade e reunida numa forma-de-vida, só é possível a partir da emancipação com relação a essa cisão. A pergunta sobre a possibilidade de uma política não estatal tem, portanto, necessariamente a seguinte forma: é possível hoje, existe hoje, algo como uma forma-de-vida, ou melhor, uma vida pela qual, em seu 
viver, esteja em jogo o próprio viver, uma vida da potência?" (AGAMBEN, 2017, p. 236).

Emancipar-se da biopolítica que, no limite, é uma tanatopolítica (AGAMBEN, 2004) ou necropolítica (MBEMBE, 2019) só é possível na superação da maquinaria e, portanto, da cisão metafísica. Logo em seguida, Agamben deixa claro que uma nova política assim constituída é uma política das formas-de-vida, isto é, aquelas em que não é possível se isolar algo como uma vida nua. Nossa época ainda experimenta estas possibilidades, ainda não saberíamos dizer se são possíveis ${ }^{10}$. Contudo, sabemos a negativa desta possibilidade de emancipar-se, que Agamben apresenta quase que como um axioma: "uma política não estatal". Ora, se o Estado é o elemento mais forte da maquinaria ontológico-biopolítica, é necessário desfazer-se dele, talvez não o enfrentar (como saber?), mas tão somente abandoná-lo, já que a ele estamos presos por esta estrutura do abandono. E mais, se a tarefa dos Estados ocidentais é, a um só tempo, política e ontológica, talvez tenhamos a chance aqui de pensar a formação humana e o processo civilizador para além, ou aquém (como saber?), da vida em sua nudez. Será possível superar uma formação humana que não se alicerce no simples fato da vida? Questão difícil, sobretudo porque no capitalismo tardio, o neoliberalismo, os processos civilizadores se voltam, cada vez mais, à reprodução daquela vida que os gregos remetiam ao campo do oikos, uma vida que somente sobrevive, ou, mesmo que satisfeita ${ }^{11}$, não possui qualquer substância ética digna deste nome, pois se contenta com um modo de vida marcado pela existência no e para o mercado, na e para a publicidade. A felicidade, que noutros tempos significava o bem da pólis, hoje é o bem privado, a mera relação de consumo.

\section{Considerações finais}

O artigo pretendeu demonstrar as convergências e indicar divergências entre o pensamento de Giorgio Agamben e de Michel Foucault. A reflexão demonstrou que, para além das características intrínsecas a cada uma das obras e do seu movimento complexo que reflete um esforço dos autores de darem conta de questões ao mesmo tempo teóricas e políticas, há muitos conceitos que apontam para uma conexão e uma identidade poderosas entre Foucault e Agamben: trata-se do cuidadoso trabalho intelectual de análise das relações de poder e do compromisso de apontar possibilidades futuras. De tal sorte que as duas obras permanecem sólidas críticas à tendência totalizante e individualizante do poder e do saber e ao mesmo tempo não se rendem ao imobilismo teórico. A genealogia da política continua sendo uma agenda contemporânea. A crítica teórica ao 
estado de exceção continua sendo uma preocupação sobretudo diante das tendências políticas conservadoras presentes em várias sociedades atuais. Por isso, o artigo conclui com um esforço de identificar as linhas de força que permitem abrir o espaço do exercício da liberdade, como compromisso teórico e político dos autores analisados. Os desafios são superar a biopolítica, a politização da vida e pensar, no presente, e para o futuro, as potências de libertação, de uma humanidade que sobreviverá ao biopoder e à vida nua. 


\section{Notas}

${ }^{1}$ Professor Associado do Departamento de Ciência Política e do Programa de PósGraduação em Ciência Política da Universidade Federal Fluminense (UFF).

2 Professor Doutor do Departamento de Sociologia e Antropologia e do Programa de Pós-Graduação em Ciências Sociais da Faculdade de Filosofia e Ciências (FFC) da Universidade Estadual Paulista (Unesp-Marília).

3 Professor Adjunto do Departamento de Fundamentos Sócio-Filosóficos da Educação da Universidade Federal de Pernambuco (UFPE).

4 A atual fase do capitalismo representa uma acumulação de dispositivos que abrangem todos os aspectos da vida humana (VALERIO, 2019, pp. 37-38).

5 "A tradição dos oprimidos nos ensina que o 'estado de exceção' em que vivemos é na verdade a regra geral. Precisamos construir um conceito de história que corresponda a essa verdade. Nesse momento, percebemos que nossa tarefa é originar um verdadeiro estado de exceção; com isso, nossa posição ficará mais forte na luta contra o fascismo" (BENJAMIN, 1985, p.226). Valeria a pena recuperar este diálogo entre Benjamin e Schmitt. Para este último, a soberania se funda sobre o paradigma da excepcionalidade, neste sentido, sua obra é uma justificação para o estado de exceção como ditadura, para o primeiro, uma concepção revolucionária de exceção é possível (LEUTÉRIO, 2014; GUSI, 2015).

6 Esta zona de indistinção que permite o surgimento do espaço vazio, o de fora incluído na norma, permite que Bruno Latour (1994) fale dos híbridos. O moderno é esta separação entre o dado natural e o dado social, por meio de um jogo duplo de tradução e purificação.

7 Ver: AGAMBEN, 2004, p. 29e ss.

8 A própria ideia de humano também é produto da máquina. (AGAMBEN, 2013), (VALERIO, 2019).

9 Faz recordar muito uma lição de Foucault acerca da Aufklärung kantiana (FOUCAULT, 2011, p. 28). A saída da menoridade é uma descrição, uma prescrição e seu preceito é uma máxima.

10 Para nós certamente algumas vidas estão à altura dessa nova política, por exemplo, o corpo trans ou o corpo deficiente. Neles, o dado biológico é imediatamente político e vice-versa.

11 Quando Kojève, em 1939 no seu seminário sobre a fenomenologia de Hegel, pensa o fim da história e o advento da pós-história, imagina esta última como o american way of life, quer dizer, não uma vida propriamente feliz, mas satisfeita. Anos mais tarde mudaria de opinião e o esnobismo japonês vem ocupar seu lugar. (KOJÉVE, 2002; AGAMBEN, 2013). 


\section{Referências Bibliográficas}

AGAMBEN, Giorgio. Estado de exceção. São Paulo: Boitempo, 2004.

AGAMBEN, Giorgio. Homo Sacer: o poder soberano e a vida nua. Belo Horizonte: UFMG, 2002.

AGAMBEN, Giorgio. A comunidade que vem. Lisboa. Presença. 1993.

AGAMBEN, Giorgio. Profanações. São Paulo. Boitempo Editorial. 2007.

AGAMBEN, Giorgio. Bartleby, escrita da potência. Lisboa. Assírio \& Alvim, 2007.

AGAMBEN, Giorgio. O que é o contemporâneo? E outros ensaios. Chapecó, SC: Argos, 2009.

AGAMBEN, Giorgio. El tiempo que resta. Madrid. Editorial Trotta. 2006.

AGAMBEN, Giorgio. Meios sem fim: notas sobre a política. Belo Horizonte. Autêntica. 2015.

AGAMBEN, Giorgio. O uso dos corpos. São Paulo: Boitempo, 2017.

ALVAREZ, Marcos César. Punição, poder e resistências: a experiência do Groupe d'Information sur les Prisons e a análise crítica da prisão. In: SCAVONE, Lucila; ALVAREZ, Marcos Cesar; MISKOLCI; Richard. O legado de Foucault. São Paulo: Editora da Unesp, 2006.

ALVES, José Cláudio Souza. Dos Barões ao extermínio: a história da violência na Baixada Fluminense. Rio de Janeiro: Ed. Sepe/ APPH-Clio, 2011.

ANTELME, Robert. A espécie humana. Rio de Janeiro/São Paulo: Record, 2013.

BATISTA, Nilo. Mídia e sistema penal. In: Revista Discursos Sediciosos. Rio de Janeiro: Revan, 2002.

BATISTA, Nilo e BATISTA, Vera Malaguti (orgs). Paz armada. Rio de Janeiro: Revan, 2012.

BENJAMIN, Walter. Obras escolhidas. Magia e técnica, arte e política. São Paulo: Brasiliense, 1985. 
BENJAMIN, Walter. O anjo da história. $2^{a}$ ed. Belo Horizonte. Autêntica Editora. 2013.

CALDEIRA, Teresa Pires do Rio. Cidade de Muros: crime, segregação e cidadania em São Paulo. São Paulo: Editora 34, 2001.

CASTRO, Edgardo. Introdução a Giorgio Agamben. Belo Horizonte. Autêntica. 2012.

DELEUZE, Gilles. Post-scriptum sur les societés de contrôle in Pourparlers: 1972-1990. Paris: Editions de Minuit, 1990.

DREYFUS, Hubert; RABINOW, Paul. Michel Foucault. Uma trajetória filosófica. Para além do estruturalismo e da hermenêutica. Rio de Janeiro: Forense Universitária, 2010.

ERIBON, Didier. Michel Foucault. Paris: Flammarion, 1989.

EWALD, François. Anatomia e corpos políticos. In: Foucault: a norma e o direito. Lisboa: Vega, 1993.

FOUCAULT, Michel. Vigiar e Punir. Rio de Janeiro: Vozes, 1979.

FOUCAULT, Michel. Microfísica do Poder. Rio de Janeiro: Graal, 1984.

FOUCAULT, Michel. Introdução à vida não-fascista. Preface. In: Gilles Deleuze e Félix Guattari. Anti-Oedipus: Capitalism and Schizophrenia, New York, Viking Press, 1977, pp. XI-XIV. Traduzido por Wanderson Flor do Nascimento.

FOUCAULT, Michel. Os intelectuais e o poder. In: Microfísica do Poder. Rio de Janeiro: Graal, 1989. 8ª Edição.

FOUCAULT, Michel. A coragem da verdade. O governo de si e dos outros II. Curso no Collége de France 1983-1984. São Paulo: Martins Fontes, 2011.

FOUCAULT, Michel. Qu'est-ce que la critique? Critique et Aufklärung. Bulletin de la Societé Française de Philosophie. Vol. 82, número 2, pp. 3563. Avr/juin 1990. Tradução de Gabriela Lafetá Borges e revisão de Wanderson Flor do Nascimento.

FOUCAULT, Michel. História da sexualidade. O uso dos prazeres. Rio de Janeiro: Graal, 2007.

FOUCAULT, Michel. História da sexualidade. O cuidado de si. Rio de Janeiro: Graal, 1985. 
FOUCAULT, Michel. A escrita de si. In: Ditos e Escritos. Ética, sexualidade e política. Volume V. Rio de Janeiro: Forense Universitária, 2004.

FOUCAULT, Michel. História da sexualidade: A vontade de saber. Trad. 7a. Edição. Rio de Janeiro: Graal, 1985.

FOUCAULT, Michel. Resumo dos cursos do Collège de France. Rio de Janeiro: Zahar, 1997.

FOUCAULT, Michel. Em defesa da sociedade. São Paulo: Martins Fontes. 1999.

GINZBURG, Carlo. Medo, reverência e poder: reler Hobbes Hoje. Conferência na Universidade Federal Fluminense. Niterói, setembro de 2006.

GRAHAM, Stephen. Cidades sitiadas. O novo urbanismo militar. São Paulo: Boitempo, 2016.

GUSI, João Antônio Ferreira. O estado de exceção de Giorio Agamben: a força da norma. Mestrado em Filosofia. Paraná: PUC, 2015.

KOJÈVE, A. Introdução à Leitura de Hegel. Rio de Janeiro: Contraponto e EDUERJ, 2002.

LATOUR, B. Jamais fomos modernos. Rio de Janeiro. E. 34. 1994.

LEMKE, Thomas. A Zone of Indistinction - A Critique of Giorgio Agamben's Concept of Biopolitics. Bloßes Leben in der globalisierten Moderne. Eine Debatte zu Giorgio Agamben's Homo Sacer. Hannover, University of Hannover, 2003.

LEUTÉRIO, Alex Pereira. Estado de exceção na obra de Giorgio Abamben. Da politização da vida à comunidade que vem. Mestrado em Direito. São Paulo: PUC, 2014.

MARTINS, Carlos José. Figurações de uma atitude filosófica não-fascista. In RAGO, Margareth; VEIGA-NETO, Alfredo (orgs). Para uma vida não-fascista. Belo Horizonte: Autêntica, 2009.

MACHADO DA SILVA, Luiz Antônio. Cidades controladas. O controle do crime violento na cidade do Rio de Janeiro. In: Le Monde Diplomatique Brasil. Número 67. Fevereiro de 2013.

RAGO, Margareth; VEIGA-NETO, Alfredo (orgs). Para uma vida não-fascista. Belo Horizonte: Autêntica, 2009. 
RAGO, Margareth; VEIGA-NETO, Alfredo. Dizer sim à existência. In: RAGO, Margareth; VEIGA-NETO, Alfredo (orgs). Para uma vida não-fascista. Belo Horizonte: Autêntica, 2009.

REVEL, Judith. Dicionário Foucault. Rio de Janeiro: Forense Universitária, 2011.

RIBEIRO, Renato Janine. Hobbes: o medo e a esperança. In: WEFFORT, Francisco (org). Os Clássicos da Política. São Paulo: Ática, 1991.

RODRIGUES, André e SIQUEIRA, Raiza. As Unidades de Polícia Pacificadora e a segurança pública no Rio de Janeiro. In: Unidades de Polícia Pacificadora: debates e reflexões. Rio de Janeiro: Comunicações do ISER, número 67, ano 31, 2012.

SANTOS, Laymert Garcia dos. Brasil contemporâneo: estado de exceção? In: A era da indeterminação. Rio de Janeiro: Boitempo, 2007.

SERRA, Carlos Henrique Aguiar. Criminologia e Direito Penal em Roberto Lyra e Nélson Hungria: uma proposta indisciplinada. Rio de Janeiro: Lumen Juris, 2008.

SERRA, Carlos Henrique Aguiar. Violência, pathos e Leviatã na contemporaneidade. In: Anais do Congresso Internacional de Psicopatologia Fundamental. Rio de Janeiro: UFF, 2008.

SOUZA, Luís Antônio F. Paradoxos da modernidade vigiada: Michel Foucault e as reflexões sore sociedade de controle, In: SCAVONE, Lucila; ALVAREZ, Marcos Cesar; MISKOLCI; Richard. O legado de Foucault. São Paulo: Editora da Unesp, 2006.

SCHMITT, C. Teologia Política. Belo Horizonte. Ed. Del Rey. 2006.

VALERIO, Raphael Guazzelli. Teoria biopolítica da formação humana. Curitiba: Editora UFPR, 2019. No prelo.

ZAFFARONI, Eugênio Raul. Em busca das penas perdidas. Rio de Janeiro: Revan, 1991. 